US Army Corps

of Engineers ${ }_{\circledast}$

Engineer Research and

Development Center

\title{
Robust Forest Cover Indices for Multispectral Images
}

Sarah J. Becker, Craig S. T. Daughtry, and Andrew L. Russ

March 2019 
The U.S. Army Engineer Research and Development Center (ERDC) solves the nation's toughest engineering and environmental challenges. ERDC develops innovative solutions in civil and military engineering, geospatial sciences, water resources, and environmental sciences for the Army, the Department of Defense, civilian agencies, and our nation's public good. Find out more at www.erdc.usace.army.mil.

To search for other technical reports published by ERDC, visit the ERDC online library at http://acwc.sdp.sirsi.net/client/default. 


\title{
Robust Forest Cover Indices for Multispectral Images
}

\author{
Sarah J. Becker \\ U.S. Army Engineer Research and Development Center (ERDC) \\ Geospatial Research Laboratory (GRL) \\ 7701 Telegraph Rd. \\ Alexandria, VA 22315-3864 \\ Craig S. T. Daughtry and Andrew L. Russ \\ USDA Agricultural Research Service (ARS) \\ Hydrology and Remote Sensing Laboratory \\ Bldg. 007, BARC-West \\ Beltsville, MD 20705-2350
}

Final Report

Approved for public release; distribution is unlimited.

Prepared for Headquarters, U.S. Army Corps of Engineers

Washington, DC 20314-1000

Under Geospatial Analysis at the Tactical Edge (GATE): 405906 and 405908, Geoenabled Augmented Intelligence for Decisive Engagement (GAIDEN):

0602784A-855-24, and Geo-Intelligence in Complex Urban Environments (GeolCUE): 62784 


\section{Abstract}

Trees occur in many land cover classes and provide significant ecosystem services. Remotely sensed multispectral images are often used to create thematic maps of land cover, but accurately identifying trees in mixed land-use scenes is challenging. We developed two forest cover indices and protocols that reliably identified trees in WorldView-2 multispectral images. The study site in Maryland included coniferous and deciduous trees associated with agricultural fields and pastures, residential and commercial buildings, roads, parking lots, wetlands, and forests. The forest cover indices exploited the product of either the reflectance in red $(630$ to $690 \mathrm{~nm})$ and red edge (705 to $745 \mathrm{~nm}$ ) bands or the product of reflectance in red and near infrared ( 770 to $895 \mathrm{~nm}$ ) bands. For two classes (trees versus other), overall classification accuracy was $>77$ percent for the four images that were acquired in each season of the year. Additional research is required to evaluate these indices for other scenes and sensors.

DISCLAIMER: The contents of this report are not to be used for advertising, publication, or promotional purposes. Citation of trade names does not constitute an official endorsement or approval of the use of such commercial products. All product names and trademarks cited are the property of their respective owners. The findings of this report are not to be construed as an official Department of the Army position unless so designated by other authorized documents. 


\section{Contents}

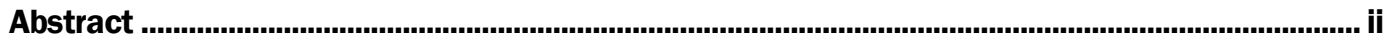

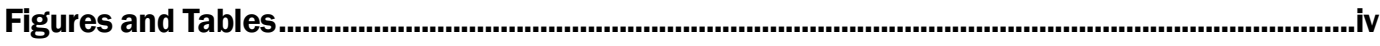

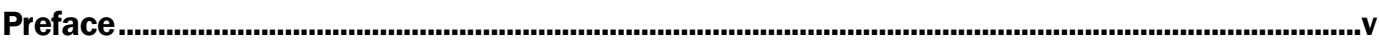

Unit Conversion Factors ......................................................................................................................vi

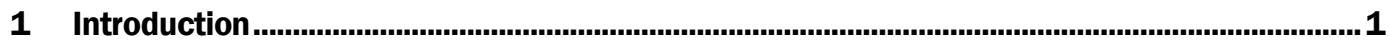

1.1 Spectral Properties of Vegetation ....................................................................... 1

1.2 Detecting Tree Cover in Multispectral Imagery .................................................. 3

1.3 Overview of Automated Tree Detection Methods................................................. 5

2 Materials and Methods................................................................................................................ 8

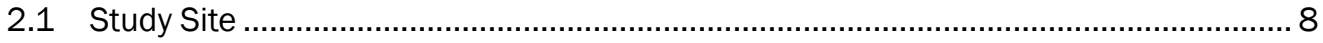

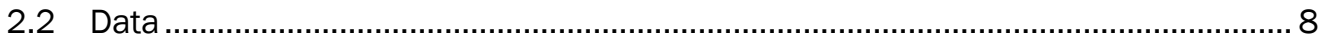

2.3 Methodology........................................................................................... 10

2.3.1 Forest Cover Indices and the Normalized Difference Vegetation Index............................ 10

2.3.2 Accuracy Assessment .............................................................................................. 11

3 Results....................................................................................................................................14

3.1 Overview of Spectral Distinctions Between Trees and Other Land Covers...............14

3.2 Forest Cover Index Output ................................................................................... 15

4 Discussion ................................................................................................................................18

4.1 Potential Causes of Spectral Separability Between Trees and Other Leafy Vegetation Cover ........................................................................................ 18

4.2 Limitations and Future Research Directions..................................................... 19

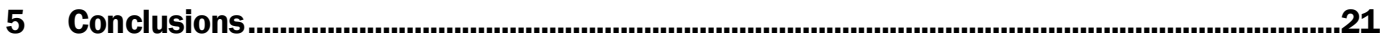

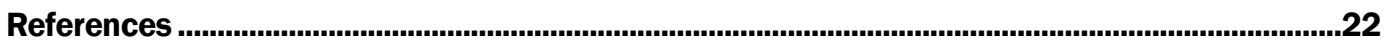




\section{Figures and Tables}

\section{Figures}

1 WorldView-2 image of Beltsville Agricultural Research Center (BARC) in Beltsville, MD from 05 August 2012

2 WorldView-2 spectral profiles of land covers taken from an average of multiple pixels in the study area from 05 August 2012 imagery....................................................14

3 This figure illustrates the steps in each part of the $\mathrm{FCl}$ workflow in a

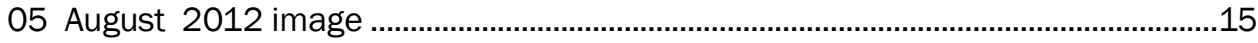

4 This figure shows the result of the FCl1 ...........................................................................15

\section{Tables}

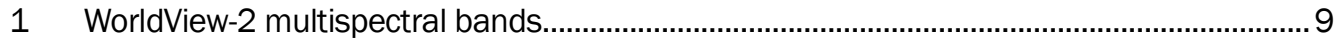

2 Categories and number of ROls selected for each tree type and other vegetative

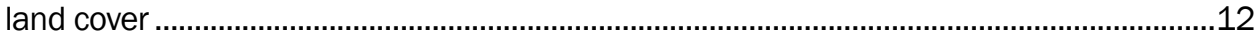

3 Producer's, user's, and overall accuracy for Tree versus Not Tree classifications using FCl1, FCl2, and NDVI on four dates ..................................... 15

4 Individual error matrix KHAT analysis results .................................................................17

5 Pairwise comparison of the error matrices .........................................................................17 


\section{Preface}

This study was performed by the Geospatial Analysis at the Tactical Edge (GATE), Geo-enabled Augmented Intelligence for Decisive Engagement (GAIDEN), and Geo-Intelligence in Complex Urban Environments (GeoICUE ) work packages; under projects GATE 405906 and 405908, GAIDEN, 0602784A-855-24, and GeoICUE, 62784.

The work was performed at the U.S. Army Engineer Research and Development Center - Geospatial Research Laboratory (ERDC-GRL). At the time of publication, Ms. Martha Kiene was the acting chief, CEERDTRS and the chief, CEERD-TR. Dr. Robert L. Fischer, CEERD-TR was the Technical Director for ERDC-GRL. The Deputy Director of ERDC-GRL was Ms. Valerie L. Carney and the Director was Mr. Gary W. Blohm.

This Miscellaneous Paper (MP) was published as the following:

Becker, S. J., C. S. T. Daughtry, and A. L. Russ. 2018. Robust forest cover indices for multispectral images. Photogrammetric Engineering \& Remote Sensing 84(8): 21-28. doi: 10.14358/PERS.84.8.393.

COL Ivan P Beckman was Commander of ERDC, and Dr. David W. Pittman was the Director. 


\section{Unit Conversion Factors}

\begin{tabular}{|l|l|l|}
\hline Multiply & By & To Obtain \\
\hline acres & $4,046.873$ & square meters \\
\hline acre-feet & $1,233.5$ & cubic meters \\
\hline feet & 0.3048 & meters \\
\hline inches & 0.0254 & meters \\
\hline inch-pounds (force) & 0.1129848 & newton meters \\
\hline miles (nautical) & 1,852 & meters \\
\hline miles (U.S. statute) & $1,609.347$ & meters \\
\hline square inches & $6.4516 \mathrm{E}-04$ & square meters \\
\hline square miles & $2.589998 \mathrm{E}+06$ & square meters \\
\hline square yards & 0.8361274 & square meters \\
\hline yards & 0.9144 & meters \\
\hline
\end{tabular}




\section{Introduction}

Trees occur in forest and non-forest land cover classes and provide significant ecosystem services, including microclimate regulation, watershed protection, wildlife habitat, and recreational uses. Trees and their locations within a landscape are also important for such diverse applications as planning routes for utilities, roads, and trails, monitoring land cover changes, and modeling environmental quality and quality of life. Remotely sensed images are often used to create thematic maps of land cover at a range of spatial and temporal scales (Foody, 2002), but accurately identifying trees in mixed land-use scenes is often challenging because tree cover is easily conflated with other types of vegetative covers in multispectral data. The focus of this research is to address this challenge with a methodology for distinguishing forest cover from other land covers (including vegetative covers) using multispectral data.

The remainder of this section reviews spectral properties of vegetation and remote sensing approaches for detecting trees to support understanding how forest cover differs spectrally from other land covers. The next section details the materials and methods used to conduct this research, including a description of the indices developed to distinguish forest cover from other land covers and how accuracy was measured, followed by a section that describes results from testing the new indices, leading to a discussion and suggestions for future research, and a final section with conclusions.

\subsection{Spectral Properties of Vegetation}

Multiple factors influence the spectral properties of forest and other vegetation matter, creating a challenge for distinguishing between them in satellite imagery. When solar radiation interacts with matter, it may be reflected, transmitted, or absorbed. The spectral reflectance of vegetation canopies is determined by: (1) spectral properties of the canopy elements; (2) canopy structure; (3) background reflectance; (4) illumination and view directions; and (5) atmospheric transmittance (Bauer, 1985). When vegetation density is high, leaves are often the primary scattering elements and the background contributes little to overall canopy reflectance. 
However, when vegetation density is low, background reflectance significantly influences canopy reflectance.

1. The spectral properties of canopy elements (i.e., leaves, stems, inflorescences) are determined primarily by the concentrations of chlorophyll and other pigments in the visible ( 400 to $700 \mathrm{~nm}$ ), leaf structure in the near infrared (700 to 1,200 nm), and amount of water in the shortwave infrared (1,200 to 2,000 $\mathrm{nm}$ ) wavelength regions (Knipling, 1970). Physiological and morphological changes occur as leaves expand, mature, and senesce, which significantly affect leaf spectral properties (Roberts et al., 1998) and could aid in distinguishing between trees and other vegetation. Nutrient deficiencies, water deficits, and damage by insects and diseases also affect the spectral properties of leaves (van Leeuwen, 2009).

2. Although the spectral properties of most healthy green leaves are roughly similar, canopy structure describes how individual canopy elements (leaves, stems, etc.) are positioned throughout the canopy and determines how radiation is transferred within and from the canopy. Differences in canopy structure could aid in distinguishing between forest and other vegetative covers. The geometrical arrangement of these canopy elements in space varies with species, age, and environmental conditions, such as nutrient and water stresses, disease, or insect damage, and wind. Characterizations of the structure of vegetation canopies often include leaf area index, fraction vegetation cover, biomass, and leaf angle distribution (Bunnik, 1978; Daughtry, 1990).

3. The lower boundary layer or background for vegetation canopies is typically soil, rock, litter, water, or understory vegetation, which impact reflectance depending on the canopy structure and density and can differ between forest and other vegetative covers. Physical factors quite different from those of green vegetation determine the reflectance of these backgrounds and are more likely to influence reflectance in less dense vegetation canopies. Five general types of soil reflectance spectra based on organic matter content, texture, and ferric iron absorption have been identified (Stoner and Baumgardner, 1981). Rocks often have unique spectral features associated with their mineral composition. Reflectance spectra of litter (non-photosynthetic vegetation) and soils are often similar and differ only in amplitude in the visible and near infrared wavelengths (Biard and Baret, 1997; Daughtry et al., 2004). In the shortwave infrared, the spectra of dry litter have absorption features associated with cellulose and lignin that are absent in spectra of soils and green vegetation (Nagler 
et al., 2000). Soils and rocks have absorption features associated with minerals that are absent in green vegetation and litter (Kokaly and Clark, 1999; Serbin et al., 2009).

4. With changing sun or view directions, the proportions of sunlit vegetation, shadowed vegetation, sunlit background, and shadowed background viewed by the sensor will vary, which could aid in distinguishing between forest and other vegetative land covers. Canopy radiance as measured by the sensor will change even when the spectral properties of canopy elements, canopy structure, and background are constant (Ranson et al., 1985). Several satellite sensors, e.g. WorldView-2 and -3, Hyperion, and SPOT, provide options for off-nadir view angles which must be considered when analyzing their images.

5. Solar radiation is partially absorbed or scattered by molecules and aerosols as it passes through the Earth's atmosphere affecting the quality of remotely sensed images of the surface. Atmospheric corrections are necessary to quantitatively analyze multi-date images, which could also aid in distinguishing between forest and other vegetative covers. For example, the Fast Line-of-sight Atmospheric Analysis of Hypercubes (FLAASH) algorithm provides a physics-based approach to atmospheric correction (Adler-Golden et al., 1998).

\subsection{Detecting Tree Cover in Multispectral Imagery}

Conventional forest inventory methods often include field measurements (e.g., diameter at breast height, crown diameter, and crown height) of many trees within the regions of interest. Manual interpretation of aerial imagery has also been used extensively for forest inventory (Wang et al., 2004). However, both techniques are labor intensive. Advances in the spatial resolution of remotely sensed images and pattern recognition algorithms have provided new opportunities for automated detection of trees.

Hyperspectral imagery (HSI) and Light Detection and Ranging (lidar) data have been used successfully for tree detection, species identification, and tree crown delineation (Ke and Quackenbush, 2011; Graves et al., 2016; Chen et al., 2006). Unfortunately, both HSI and lidar data are not widely available and are often costly to acquire for large areas. Recently, advanced multispectral imagery (MSI) with fine spatial resolution has become available commercially and may provide a low-cost alternative to HSI and lidar. 
Prior research has tested identification of trees in MSI in mixed land cover areas and while results have been promising, confusion between forest cover, including individual trees, and select land covers persists. Yuan et al. (2005), Ye et al. (2014), Fu et al. (2014), and Gonzalez-Alonso and Cuevas (1993) included forest in testing with Landsat to map different land covers, while Wu et al. (2017) and Akar et al. (2017) used WorldView2 , as explained in the following paragraphs.

Yuan et al. (2005) used a combined supervised-unsupervised training approach to map land covers in Minneapolis-St. Paul, MN using Landsat Thematic Mapper and Landsat Enhanced Thematic Mapper imagery and reported forest cover user's and producer's accuracies of 90 percent and above during their time series. While accuracies were high, they found that forest cover was most commonly confused with agriculture followed by wetland and urban land covers and less commonly confused with water and grass. They also did not identify individual trees, as the resolution of Landsat is inadequate for this purpose.

Ye et al. (2014) developed a forest index using Landsat Thematic Mapper and Landsat Enhanced Thematic Mapper comparing forested to nonforested lands and the user's and producer's accuracies were over 95 percent accurate, but they did not identify individual trees. Fu et al. (2014) used Landsat 5 and 7 to map urban, agriculture, rangeland, barren, ice/snow, and forest area using a supervised classification. User's and producer's accuracies for forest cover across the time series were between 77 percent and 95 percent. Most of the confusion occurred between forest and rangeland with no ability to identify individual trees.

Gonzalez-Alonso and Cuevas (1993) applied regression methods to Landsat to examine conifers, green oak trees, various crop covers, fallow, and river. Their tree cover results were highly accurate at over 95 percent correctly classified, but they did not identify individual trees.

Wu et al. (2017) and Akar et al. (2017) used WorldView-2 to classify land covers and included forest in their land cover testing. Wu et al. (2017) applied a support vector machine to WorldView-2 and WorldView-2 fused with lidar to classify an image that contained buildings, trees, road/parking lots, grasslands, and bare soils. User's and producer's accuracies were between 83 percent and 85 percent for trees for WorldView-2 alone, which increased when fused with lidar. Confusion 
with WorldView-2 alone happened between trees and most land covers. Individual trees were often confused with grassland.

Akar et al. (2017) merged WorldView-2 MSI with panchromatic imagery and used a support vector machine to classify an image that contained forest, rangeland, and other land covers. They found that user's and producer's accuracies for forest were 86 percent and 89 percent and with the most confusion being with rangeland. Individual trees were among the pixels misclassified as rangeland.

\subsection{Overview of Automated Tree Detection Methods}

Ke and Quackenbush (2011) defined tree detection algorithms as procedures for finding treetops or locating trees without necessarily delineating tree-crown outlines. They also identified four broad categories of automatic tree detection methods: (1) local maximum filtering, (2) image binarization, (3) scale analysis, and (4) template matching. Many of these methods rely on imagery from aerial sensors or cameras, which is usually higher in spatial resolution but more difficult to acquire on a repeat basis than satellite imagery. The methods varied in their ability to correctly identify trees and reliably differentiate between trees and other vegetation.

For the local maximum filtering method, the maximum pixel value within a moving window is assumed to represent the sunlit treetop. First, vegetative land covers are identified using a supervised or unsupervised classification and then local maxima of various combinations of visible and near infrared bands within the vegetative land cover are used to delineate trees. Pouliot et al. (2005) used color infrared imagery with pixel sizes of 6 $\mathrm{cm}$. The percent correct in the color infrared imagery ranged from 40.6 to 90.4 percent for regenerating cutover trees depending on the tree cover (Pouliot et al., 2005).

Image binarization is a straightforward thresholding approach where grayscale is converted into black-and-white imagery and pixels on one side of the threshold represent pixels of interest, while pixels on the other side of the threshold are background. When used to separate trees from other land covers, the contrast between trees and background can vary within an image, which can cause only partial success when one threshold value is applied throughout the image (Ke and Quackenbush, 2011). Pitkanen (2001) performed image smoothing on grayscale digital imagery $(0.5 \mathrm{~m}$ 
pixel size) and separated trees from the rest of the image using a binarization to keep the maximum values in the image. He achieved overall accuracies of 50 to 96 percent depending on the threshold method.

Other studies combined local maximum filtering and binarization. Pouliot et al. (2002) took the absolute difference of the near infrared and red bands in color infrared imagery ( $5 \mathrm{~cm}$ pixel size) and thresholded trees using a local maximum filter on the image with accuracies that ranged from 39.4 to 88.9 percent for detecting trees. Following earlier work by Carter (1994), Bunting and Lucas (2006) applied red edge and red band ratios and selected the maximum value in hyperspectral imagery with a pixel size of $1 \mathrm{~m}$ and achieved an accuracy of 19.2 to 91.6 percent in delineating tree crowns depending on the stem diameter at breast height. Wang et al. (2004) performed a principal components analysis on a hyperspectral image to create a single band and applied image maxima techniques to extract forest cover with an accuracy of 75.6 percent.

Image scale issues influence accuracy of tree detection and arise when trees are of different sizes, as small trees can be missed. Pouliot and King (2005) used a local smoothing factor and incremental Gaussian smoothing on color infrared digital imagery to examine tree detection when trees were large compared to the ground pixel size. They performed their testing on imagery ranging from 5 to $15 \mathrm{~cm}$ pixels and found that smaller pixel sizes brought the overall accuracy up to 96.4 percent from 58.5 percent depending on the tree cover and smoothing algorithm.

Template matching is an object-based image processing technique where parts of an image match a template. Quackenbush et al. (2000) developed templates by selecting typical trees in $1.0 \mathrm{~m}$ digital imagery and applied those templates to different areas in an image. User accuracies were between 86.5 and 94.8 percent depending on which template matching technique they used.

Local maximum filtering, image binarization, scale analysis, and template matching generally work best when the spatial structure of the trees is relatively uniform (i.e., evenly spaced and similarly aged) and consists primarily of bright tree crowns and dark shaded gaps. Tree detection often degrades significantly when tree size and shape vary greatly (Ke and Quackenbush, 2011). 
In addition to spectral-based methods to identify trees, image type and pixel size are relevant to image-based tree detection. If pixels are too small, tree trunks or branches and spacing between rows of agriculture could become visible causing problems with classifications. If pixels are too large, individual trees are not discernible. Ke and Quackenbush (2011) reviewed 40 applications of tree crown detection and delineation research and found that a ground surface distance (GSD) of 0.5 to $0.7 \mathrm{~m}$ was most commonly used. This was partially due to the extensive use of Compact Airborne Spectrographic Imager, an airborne sensor that has a GSD of 0.6 $\mathrm{m}$, and also due to the diameter of tree crowns, which were around a few meters in diameter, allowing multiple pixels to fit within each crown so that it becomes distinguishable (Ke and Quackenbush, 2011).

In summary, the methods described in the literature above do not provide a reliable way to distinguish trees associated with agricultural fields and pastures, residential and commercial buildings, roads, parking lots, and wetlands using commercial satellite imagery. This study's objective is to develop and test forest cover indices that can reliably distinguish forest cover from other land covers using WorldView-2 imagery, which is coarser in spatial resolution than the imagery types discussed in this section. 


\section{Materials and Methods}

\subsection{Study Site}

The U.S. Department of Agriculture (USDA) Henry A. Wallace Beltsville Agricultural Research Center (BARC) is near Beltsville, MD $\left(39.025^{\circ} \mathrm{N}\right.$, $76.850^{\circ} \mathrm{W}$ ) and includes $>2500$ hectares of agricultural fields and pastures; conifer and deciduous woodlands; wetlands; and some urban features, such as buildings, roads, and parking lots. Surrounding the BARC are additional urban features including residential and commercial buildings and infrastructures (Figure 1). Typical soil has a sandy-textured surface layer and a taxonomic classification of coarse-loamy, siliceous, mesic Typic (or Aquic) Hapludults (Soil Survey Staff, 2018). The climate is humid subtropical with precipitation occurring throughout the year (Weatherbase, 2017). The study site is located in the coastal plain and consists of fairly flat to gently sloping uplands.

\subsection{Data}

The Worldview-2 satellite hosts an 8-band multispectral sensor that measures reflectance in the visible and near infrared regions of the electromagnetic spectrum from 400 to $1,040 \mathrm{~nm}$ with $1.85 \mathrm{~m}$ spatial resolution at nadir (Table 1). Although WorldView-2 can collect images up to 40-degrees off-nadir (eoPortal Directory, 2017), the images analyzed were acquired between 11.5 and 31.5 degrees off-nadir. A total of 13 World View-2 images acquired between May 2012 and May 2015 were analyzed. Four images were selected that represented each season and the major phenological changes in vegetation during a year. The spring image was from 27 May 2012, summer was from 05 August 2012, fall was from 26 October 2014, and winter was from 18 January 2013. 
Figure 1. WorldView-2 image of Beltsville Agricultural Research Center (BARC) in Beltsville, MD from 05 August 2012.

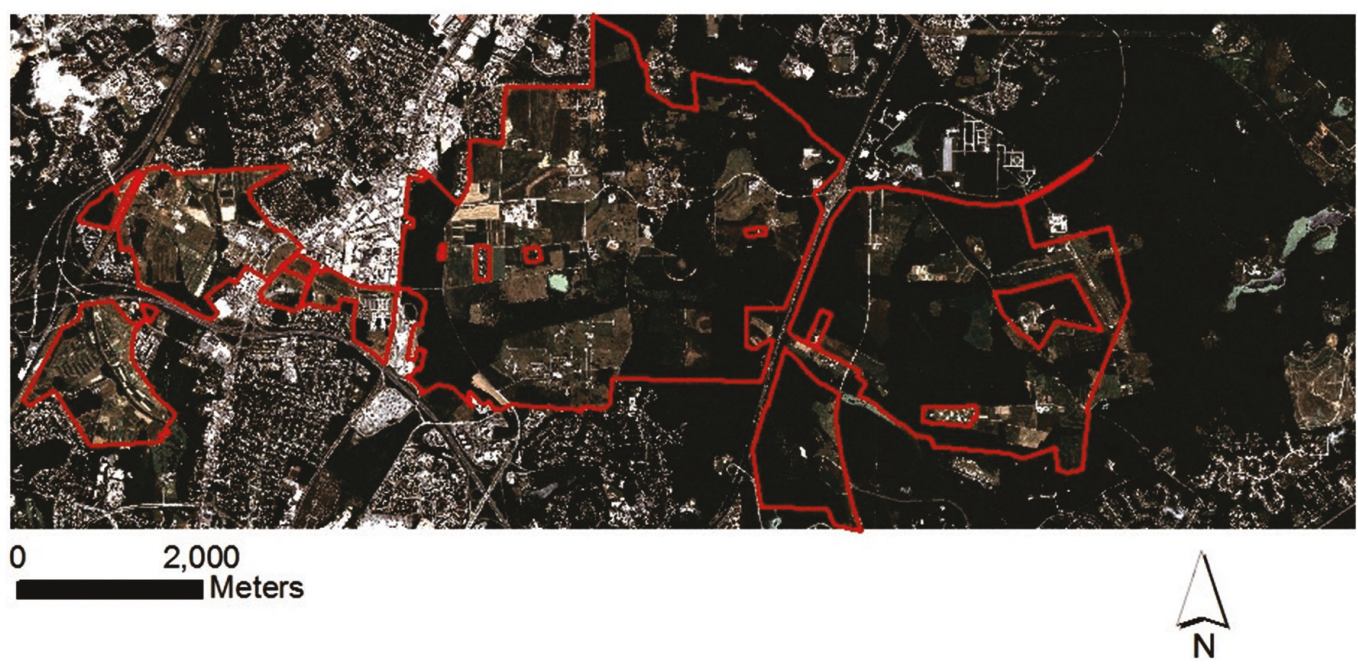

Table 1. WorldView-2 multispectral bands.

\begin{tabular}{|l|l|l|l|}
\hline Band Name & Band \# & ${ }^{*}$ FWHM $(\mathbf{n m})$ & Band Center $(\mathbf{n m})$ \\
\hline Coastal blue & 1 & $400-450$ & 425 \\
\hline Blue & 2 & $450-510$ & 480 \\
\hline Green & 3 & $510-580$ & 545 \\
\hline Yellow & 4 & $585-625$ & 605 \\
\hline Red & 5 & $630-690$ & 660 \\
\hline Red Edge & 6 & $705-745$ & 725 \\
\hline Near Infrared-1 & 7 & $770-895$ & 835 \\
\hline Near Infrared-2 & 8 & $860-1,040$ & 950 \\
\hline
\end{tabular}

*FWHM $=$ full width at half maximum.

The Worldview-2 images were orthorectified to the Universal Transverse Mercator coordinate system, calibrated to at-sensor radiance values, and atmospherically corrected to surface reflectance using the FLAASH module in the commercial software, Environment for Visualizing Images (ENVI) (Harris Corporation, Melbourne, Florida). All remote sensing analyses were performed in ENVI. 


\subsection{Methodology}

\subsubsection{Forest Cover Indices and the Normalized Difference Vegetation Index}

The Forest Cover Index 1 (FCI1) and Forest Cover Index 2 (FCI2) were developed to separate forest from other land covers using the following equations:

$$
\begin{aligned}
\mathrm{FCI} 1 & =\mathrm{R}_{660} * \mathrm{R}_{725} \\
\mathrm{FCI} 2 & =\mathrm{R}_{660} * \mathrm{R}_{835}
\end{aligned}
$$

where $\mathrm{R}_{660}, \mathrm{R}_{725}$, and $\mathrm{R}_{835}$ are reflectance in Red, Red Edge, and Near Infrared-1 bands, respectively (Table 1 ). These equations were developed after visually comparing spectra of tree cover to those of other vegetation. While spectral profiles for trees were similar to spectral profiles for other vegetative cover, the red, red edge, and near infrared reflectance values for trees were consistently lower. Traditional vegetation indices, simple ratios, and normalized difference indices do not exploit the difference between trees and other land covers. We found that multiplying reflectance in the pairs of bands emphasized the difference between trees and other vegetative land covers.

The Normalized Difference Vegetation Index (NDVI) (Rouse et al., 1974) provides a measure for vegetative vigor and is frequently used to delineate green vegetation from non-vegetation and occasionally used to delineate trees from other land covers (Peters et al., 2002; White et al., 2016; Bandyopadhyay et al., 2013). NDVI was calculated using the following equation:

$$
\mathrm{NDVI}=\left(\mathrm{R}_{835}-\mathrm{R}_{660}\right) /\left(\mathrm{R}_{835}+\mathrm{R}_{660}\right)
$$

Where, $\mathrm{R}_{660}$ and $\mathrm{R}_{835}$ are reflectance in Red and Near Infrared-1 bands, respectively (Table 1).

In the FCI1 and FCI2 images, darker areas corresponded to trees and dense vegetation while brighter areas corresponded to other vegetative features, including agriculture and grasses. With this knowledge, a binary system was created to mask out forest cover while retaining other land 
covers in the FCI1 and FCI2 images using the steps below. The same steps were also applied to the NDVI images.

1. Different land covers in the image were examined to determine a userdefined threshold value that separated trees from other vegetation covers.

2. A mask was built to separate out trees below the threshold value.

3. A 200-pixel $\left(800 \mathrm{~m}^{2}\right)$ group minimum and 8-neighbor sieve were applied to the resulting image to remove small clusters of other land cover pixels that should have been identified as trees. The group minimum is the smallest size grouping to keep. After reviewing the distribution of land covers in the test site, a group minimum of 200 pixels was chosen. An 8neighbor sieve consists of all of the pixels immediately adjacent to the original pixel and it removes the entire group if the pixels are grouped in the same class.

4. A $3 \times 3$ pixel clump was executed to fill in small areas of other land cover pixels that were incorrectly identified as trees. This clump size was large enough to fill in erroneously identified pixels while retaining many individual trees and most small tree groups.

5. The resulting output from Step 4 was used to apply a mask to the original image, which resulted in an image that masked all of the trees.

\subsubsection{Accuracy Assessment}

We selected 66 regions of interest (ROI) of various sizes within the study area to assess the accuracy of these indices for classifying trees from a broad range of other vegetative land covers for each season of the year (Table 2). Approximately 100,000 pixels were included in these 66 ROIs; however the number varied slightly from date to date due to view angles and clouds. The 'Tree' category included 10 conifer and 10 deciduous ROIs. The 'Not-Tree' category included 30 ROIs of annual crops (alfalfa, barley, corn, orchardgrass, rye, ryegrass, soybean, turf grass, triticale, and wheat), 10 perennial grass pastures, and 6 golf courses. 
Table 2. Categories and number of ROls selected for each tree type and other vegetative land cover.

\begin{tabular}{|c|c|c|c|c|}
\hline \multicolumn{5}{|c|}{ Pixels in ROI } \\
\hline ROI & 27-May-12 & 5-Aug-12 & 26-Oct-14 & 18-Jan-13 \\
\hline \multicolumn{5}{|l|}{ Tree } \\
\hline Evergreen $^{1}$ & 4,513 & 3,992 & 4,301 & 2,790 \\
\hline Deciduous $^{2}$ & 34,492 & 31,106 & 32,900 & 21,350 \\
\hline \multicolumn{5}{|l|}{ Not Tree } \\
\hline Perennial $^{3}$ & 16,628 & 14,368 & 15,510 & 9,946 \\
\hline Annual $^{4}$ & 46,002 & 41,267 & 43,644 & 28,494 \\
\hline
\end{tabular}

1 Evergreen trees are primarily coniferous trees including shortleaf pines and Virginia pines.

2 Deciduous trees are primarily broadleaf trees including oaks, maples, hickory, poplars, and sweetgums.

3 Perennial vegetation class included cool season grass pastures, alfalfa, and turf grasses.

${ }^{4}$ Annual crop class included corn, soybeans, and small grains (barley, oats, rye, triticale, wheat).

The accuracy assessment consisted of a comparison of tree pixels to other vegetation pixels, which were recoded to "Not Tree." The USDA maintains records of land uses in the BARC, which provided ground truth for the other vegetation pixels. Error was calculated for FCI1, FCI2, and NDVI by using the 66 ROIs for the four dates. User's accuracy is a measure of the probability that a pixel classified in an image represents that category on the ground. Producer's accuracy is the probability a reference pixel is correctly classified. Overall accuracy looks at the total number of correctly identified pixels compared to the total number of reference pixels. KHAT is a comparison of actual agreement between the computer classification of land cover and reference data and chance agreement between the computer classification and reference data (Congalton et al., 1983). The KHAT statistic, its variance, and Z-statistic for a single error matrix were computed to determine if agreement between the remote sensing classification and the surface reference data was significantly better than random (Congalton and Green, 2008). Non-vegetative ROIs were not selected.

The error matrices of three indices were also tested to determine if they differed significantly and to determine which was most accurate. The Zstatistic for testing pairs of error matrices was calculated as:

$$
z=\frac{K H A T_{1}-K H A T_{2}}{\sqrt{\operatorname{var}\left(K H A T_{1}\right)+\operatorname{var}\left(K H A T_{2}\right)}}
$$


Where $\mathrm{KHAT}_{1}$ and $\mathrm{KHAT}_{2}$ are estimates of the Kappa statistic and $\operatorname{var}\left(\mathrm{KHAT}_{1}\right)$ and $\operatorname{var}\left(\mathrm{KHAT}_{2}\right)$ are estimates of the variance for index \#1 and index \#2, respectively (Congalton and Green, 2008). We compared FCI1 to FCI2, FCI1 to NDVI, and FCI2 to NDVI and used $\mathrm{Z} \geq 1.96$ ( $\mathrm{p} \leq \mathrm{0.05}$ ) to determine which ones were significantly different. 


\section{Results}

\subsection{Overview of Spectral Distinctions Between Trees and Other Land Covers}

All healthy green vegetation follows roughly the same shaped spectral curve with variations based on factors such as health, water content, and structure of the mesophyll layer (Figure 2; Knipling, 1970). In Figure 2, green vegetation has low reflectance in the visible (400 to $700 \mathrm{~nm}$ ) portion in the electromagnetic spectrum, before increasing sharply into the near infrared (700 to $1,100 \mathrm{~nm}$ ) portion making it distinct from other land covers (Dozier, 1989; Huete and Jackson, 1987; and Nagler et al., 2000). The red edge band (Table 1) captures the transition between the red and near infrared bands and provides additional information about plant chlorophyll status (Horler et al., 1983), which may help distinguish between vegetation covers. Pu and Landry (2012) used WordView-2 to map urban tree species and found that the presence of the red edge band improved the results. Heenkenda et al. (2014) substituted the red edge for the red band in the NDVI and differentiated between home gardens and other vegetation. These variations are unique enough to discriminate forest cover from other vegetation types and can be exploited with the development of a spectral index.

Figure 2. WorldView-2 spectral profiles of land covers taken from an average of multiple pixels in the study area from 05 August 2012 imagery.

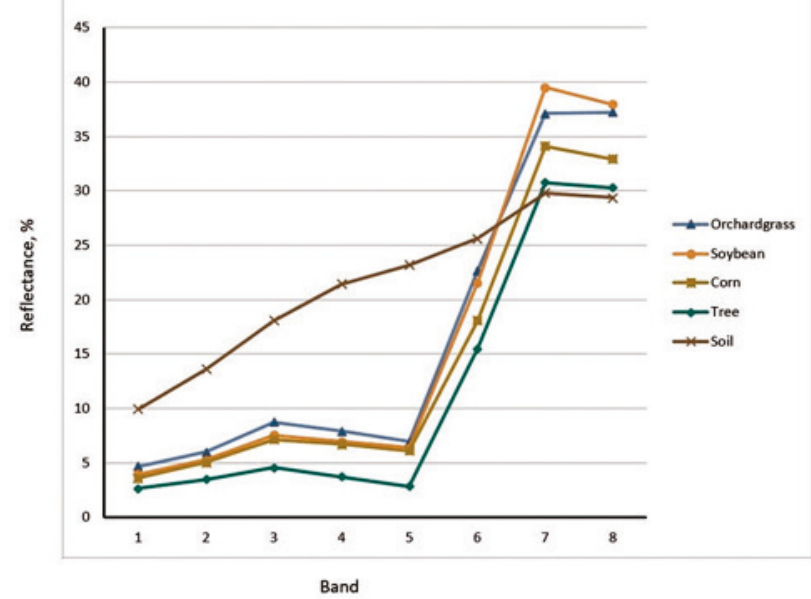


Figure 3. This figure illustrates the steps in each part of the $\mathrm{FCl}$ workflow in a 05 August 2012 image.

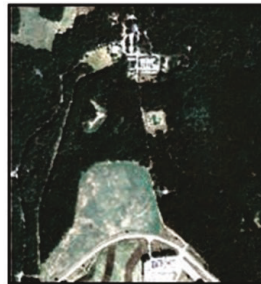

(a) Original image

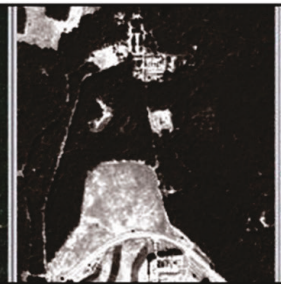

(b) FCI1 raw output

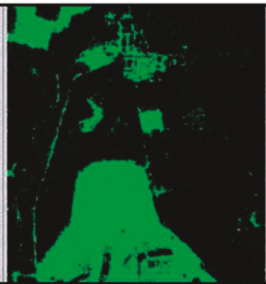

(c) Pre-sieve/clump

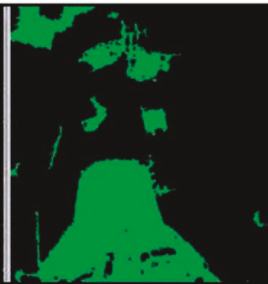

(d) Post-sieve/clump

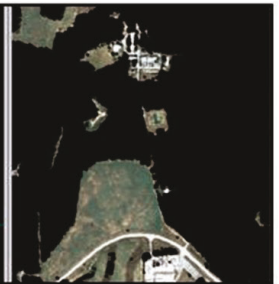

(e) Final result

Figure 4. This figure shows the result of the FCl1.

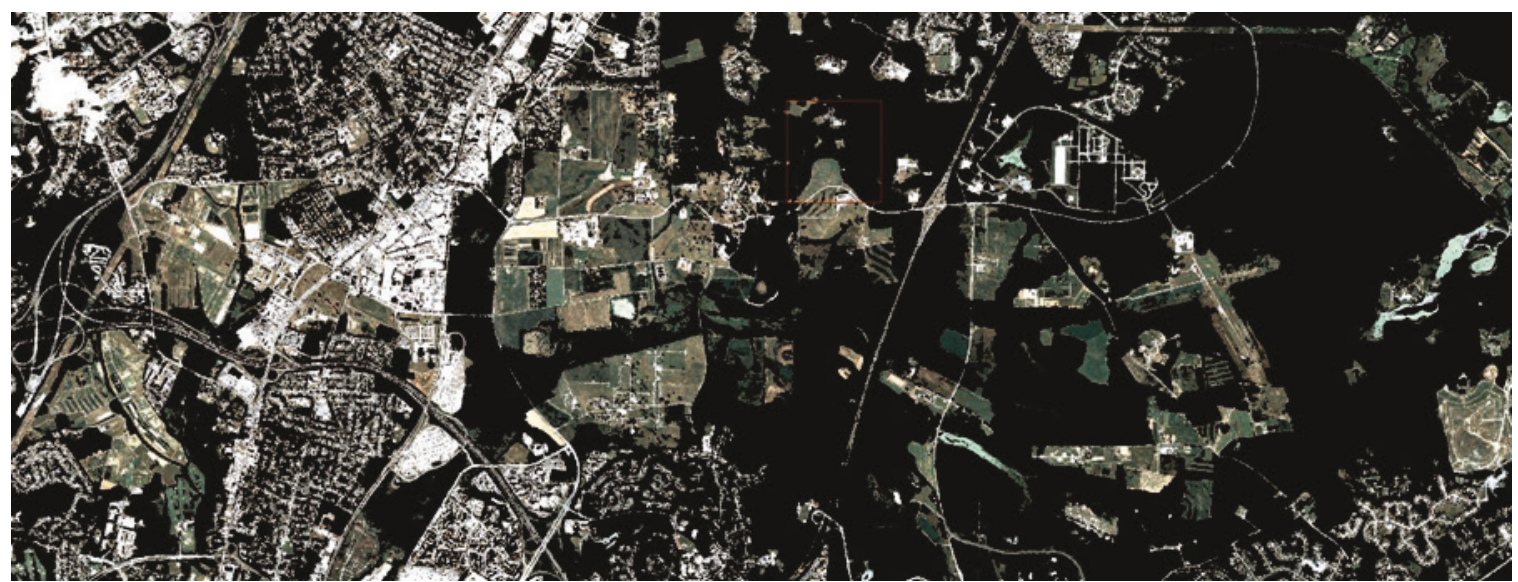

Table 3. Producer's, user's, and overall accuracy for Tree versus Not Tree classifications using $\mathrm{FCl} 1, \mathrm{FCl} 2$, and NDVI on four dates.

\begin{tabular}{|c|c|c|c|c|c|c|c|c|c|c|}
\hline \multirow[t]{2}{*}{ Date } & \multirow[t]{2}{*}{ Class } & \multicolumn{3}{|c|}{ Producer's Accuracy (\%) } & \multicolumn{3}{|c|}{ User's Accuracy (\%) } & \multicolumn{3}{|c|}{ Overall Accuracy (\%) } \\
\hline & & FCl1 & $\mathrm{FCl} 2$ & NDVI & FCl1 & $\mathrm{FCl} 2$ & NDVI & $\mathrm{FCl} 1$ & $\mathrm{FCl} 2$ & NDVI \\
\hline \multirow{2}{*}{$\begin{array}{l}27 \text { May } \\
2012\end{array}$} & Tree & 95.1 & 99.4 & 88.1 & 99.1 & 74.1 & 94.7 & 97.8 & 86.4 & 95.2 \\
\hline & Not Tree & 99.5 & 78.2 & 99.7 & 97.0 & 99.5 & 93.0 & & & \\
\hline \multirow{2}{*}{$\begin{array}{l}05 \text { Aug } \\
2012\end{array}$} & Tree & 99.9 & 99.9 & 99.4 & 89.2 & 92.1 & 54.3 & 95.3 & 96.7 & 67.3 \\
\hline & Not Tree & 92.4 & 94.6 & 47.1 & 99.9 & 99.9 & 99.3 & & & \\
\hline \multirow{2}{*}{$\begin{array}{l}26 \text { Oct } \\
2014\end{array}$} & Tree & 99.8 & 99.9 & 99.9 & 72.0 & 62.8 & 61.2 & 84.9 & 77.1 & 75.9 \\
\hline & Not Tree & 75.6 & 62.7 & 60.1 & 99.8 & 99.9 & 99.9 & & & \\
\hline \multirow{2}{*}{$\begin{array}{l}18 \mathrm{Jan} \\
2013\end{array}$} & Tree & 99.9 & 99.9 & 99.9 & 89.9 & 99.4 & 41.8 & 95.7 & 99.8 & 46.3 \\
\hline & Not Tree & 93.0 & 99.6 & 12.5 & 99.9 & 99.9 & 99.9 & & & \\
\hline
\end{tabular}

\subsection{Forest Cover Index Output}

The workflow to apply the FCI1 and FCI2 to imagery yielded raster images in which pixels containing trees were successfully masked while pixels containing other vegetative land covers remained visible (Figures 3 and 4). 
Tree pixels were among the darkest pixels in the imagery with the majority of other pixels yielding brighter values. Overall accuracies for the FCI1 were over 95 percent in late May, including when agriculture was preharvest and less dense than surrounding forest cover, and in December and January, when there was little agriculture to confuse with forest cover. Results for the FCI2 were similar to FCI1 in August, December, and January imagery and were somewhat lower in late-May (Table 3). Trees were the majority of the darkest pixels in the FCI outputs for each scene, which allowed the user to reliably set a threshold separating trees from other vegetative covers. Dark vegetation features that were present in the imagery in small amounts, such as dense agriculture, in some instances were confused with forest cover in the FCI1 and FCI2 outputs. These pixel values were low, similar to those of tree pixels.

Forest cover identification using the NDVI yielded low accuracy in three of the four images. In the 27 May image, NDVI was roughly as accurate as the FCI1 output. Upon further inspection of the output image, this was because most agricultural fields were not yet planted or freshly planted with little crop emergence, while leaves were already growing on trees. These factors created a difference between the NDVI values of trees and other vegetative land covers.

The $Z$ test of statistically significantly different KHAT values indicated the NDVI and FCI tests were statistically significantly different from each other (Table 4) and in almost all comparisons, the FCI tests outperformed NDVI (Table 5). 
Table 4. Individual error matrix KHAT analysis results.

\begin{tabular}{llllll}
\hline Date & & KHAT & Variance & Z-statistic & p-value \\
\hline \multirow{4}{*}{ 27 May 2012 } & FCl1 & 0.95 & $0.97 \mathrm{E}-06$ & 969.2 & $<0.001$ \\
& FCl2 & 0.73 & $4.48 \mathrm{E}-06$ & 344.6 & $<0.001$ \\
& NDVI & 0.90 & $2.08 \mathrm{E}-06$ & 622.1 & $<0.001$ \\
\hline & FCl1 & 0.90 & $2.08 \mathrm{E}-06$ & 627.0 & $<0.001$ \\
05 Aug 2012 & FCl2 & 0.93 & $1.52 \mathrm{E}-06$ & 753.7 & $<0.001$ \\
& NDVI & 0.40 & $10.7 \mathrm{E}-06$ & 123.1 & $<0.001$ \\
\hline \multirow{3}{*}{ 26 Oct 2014 } & FCl1 & 0.71 & $4.95 \mathrm{E}-06$ & 317.2 & $<0.001$ \\
& FCl2 & 0.57 & $6.85 \mathrm{E}-06$ & 215.9 & $<0.001$ \\
& NDVI & 0.54 & $7.16 \mathrm{E}-06$ & 203.5 & $<0.001$ \\
\hline \multirow{3}{*}{ 18 Jan 2013 } & FCl1 & 0.91 & $2.81 \mathrm{E}-06$ & 543.6 & $<0.001$ \\
& FCl2 & 0.99 & $0.16 \mathrm{E}-06$ & 2500.1 & $<0.001$ \\
& NDVI & 0.10 & $44.1 \mathrm{E}-06$ & 15.0 & $<0.001$ \\
\hline
\end{tabular}

Table 5. Pairwise comparison of the error matrices.

\begin{tabular}{|c|c|c|c|c|c|c|c|c|c|}
\hline \multirow[t]{2}{*}{ Date } & \multicolumn{2}{|c|}{ FCl1 vs FCl2 } & \multirow[b]{2}{*}{$\begin{array}{l}\text { Better } \\
\text { index }\end{array}$} & \multicolumn{3}{|c|}{ FCl1 vs NDVI } & \multicolumn{3}{|c|}{$\mathrm{FCl} 2$ vs NDVI } \\
\hline & $z$ & $p$ & & $z$ & $p$ & $\begin{array}{l}\text { Better } \\
\text { index }\end{array}$ & $z$ & $p$ & $\begin{array}{c}\text { Better } \\
\text { index }\end{array}$ \\
\hline 27 May 2012 & 95.9 & $<0.001$ & $\mathrm{FCl} 1$ & 32.1 & $<0.001$ & $\mathrm{FCl} 1$ & -65.5 & $<0.001$ & NDVI \\
\hline 05 Aug 2012 & -14.4 & $<0.001$ & $\mathrm{FCl} 2$ & 139.7 & $<0.001$ & $\mathrm{FCl} 1$ & 150.6 & $<0.001$ & $\mathrm{FCl} 2$ \\
\hline 26 Oct 2014 & 41.0 & $<0.001$ & $\mathrm{FCl} 1$ & 46.3 & $<0.001$ & $\mathrm{FCl} 1$ & 5.5 & $<0.001$ & $\mathrm{FCl} 2$ \\
\hline 18 Jan 2013 & -49.2 & $<0.001$ & $\mathrm{FCl} 2$ & 118.4 & $<0.001$ & $\mathrm{FCl} 1$ & 134.6 & $<0.001$ & $\mathrm{FCl} 2$ \\
\hline
\end{tabular}




\section{Discussion}

In this study, methods were created and tested to differentiate forest from other vegetative land covers in a diverse land-use scene. Forest delineation was possible by creating new vegetation indices that exploited the product of the red and red edge bands (FCI1), and the red and first near infrared bands (FCI2) of the WorldView-2 satellite. In this study, FCI1 and FCI2 delineated forest cover throughout the year, including during times when forest is spectrally similar to other vegetation covers. NDVI was less successful than the FCI1 for all imagery dates, and less successful than the FCI2 in the August, October, and January imagery. The results give an added value over previous studies that mask out forest cover in imagery by offering a method that does not require HSI or lidar data and can use archived MSI.

\subsection{Potential Causes of Spectral Separability Between Trees and Other Leafy Vegetation Cover}

With FCI1 and FCI2, forest cover was consistently separable from other vegetation cover as shown in Tables 3, 4, and 5. Prior research comparing a canopy to an individual leaf has shown that trees have lower overall reflectance than that of an individual leaf because of radiation variations caused by illumination angle, differing leaf orientations within the canopy, shadows, and non-foliage backgrounds (Knipling, 1970).

Shadowing decreases the overall spectral curve (Zhang et al., 2015) and foliage within trees and entire tree canopies creates more shadows within trees than in agricultural crops, which have less height and foliage. Zhang and $\mathrm{Hu}$ (2012) used high spatial resolution imagery but found problems with identifying trees because of shadows when using NDVI to identify trees. For this research, shadowing within tree canopies was used to distinguish between trees and other vegetation cover types. Even in the winter when deciduous trees had lost their leaves, shadowing among branches remained, allowing trees to remain distinguishable from other land covers. NDVI accuracy was low for almost all imagery dates because NDVI values for tree and other vegetative covers were similar. In the late May image, NDVI accuracy was higher than the rest of the year, because foliage had returned to trees but many agricultural fields remained unplanted or were newly planted and crops were immature. 
Additionally, soil is typically more visible in agriculture than forest cover, especially before crops reach maturity, and both wet and dry soil typically are higher in the red region of the electromagnetic spectrum (Roberts et al., 1993; Huete, 1986) than is green vegetation.

Therefore, a pixel that contains soil and green vegetation has a higher red reflectance value, which was evident in the spectral profiles of agricultural and other non-tree vegetative pixels throughout the imagery (see Figure 2 for a comparison of a tree spectral profile to a profile of other vegetative spectra). This could have been another factor that led agriculture to be spectrally separable from forest cover.

\subsection{Limitations and Future Research Directions}

Our study site was predominately conifer and deciduous trees with closed canopies, and agricultural fields with annual and perennial crops, which contributed to the high level of accuracy of the FCI1 and FCI2.

Additionally, the study site had little topographic relief which minimized variations in reflectance caused by the presence of both sunlit and shaded slopes. Since the success of FCI1 and FCI2 in separating tree cover from other vegetative covers is partially due to shadowing, it is possible that topographic shadowing would complicate this in a less flat environment. This research tested WorldView-2 imagery that was between 11.5 and 31.5 degrees off-nadir, and did not examine how increasing the off-nadir view angle beyond 31.5 would impact the ability of the FCI1 and FCI2 to detect forest and individual tree cover, as a larger off-nadir view angle increases the pixel size and makes shadowing more extreme.

Future research will examine other environments with variation in terrain, locations that contain a variety of vegetative land covers that could be misclassified as trees, and areas with a less dense tree canopy and wider variety of tree species. Additional research will explore optimizing threshold derivation without user input to automatically identify the ideal threshold, and a comparison of the FCI1 and FCI2 to other vegetation indices beyond NDVI. Histograms have been used in prior research to threshold imagery (Kittler and Illingworth, 1986).

Future research will also include testing of the FCI2 with other sensors that contain bands in the red and near infrared regions of the electromagnetic spectrum, such as Landsat. 
Since Landsat imagery is lower in spatial resolution than WorldView-2, it could be useful in identifying forest cover but not for locating individual trees. Landsat also provides open access to an archive with global coverage, which WorldView-2 does not. 


\section{Conclusions}

A methodology was developed to identify trees to mask out forest cover in commercial MSI. The method is a straightforward binary approach using two newly developed indices, FCI1 and FCI2, where the user applies the indices to WorldView-2 imagery and defines a threshold to separate forest from other vegetative land covers. The results indicate FCI1 and FCI2 are more effective than using a traditional vegetation index, like NDVI, and are accurate throughout the year in differentiating between trees and other vegetative land covers. FCI1 and FCI2 are also effective in identifying individual trees. Previous research in tree detection has been less successful in doing so due to spectral overlap between trees and other vegetative covers or spatial resolution limitations. This methodology circumvents the need for HSI and lidar data to identify trees and will aid in efforts to map agriculture and deforestation, identify trees in an urban environment, and assist in vehicular route modeling. Future research will focus on testing FCI1 and FCI2 on diverse land covers and locations, employing lower resolution but freely available Landsat imagery, and using histograms to optimize threshold derivation between tree and other land covers without user input. 


\section{References}

Adler-Golden, S., A. Berk, L.S. Bernstein, S. Richtsmeier, P.K. Acharya, M.W. Matthew, G.P. Anderson, C.L. Allred, L.S. Jeong, and J.H. Chetwynd, 1998. FLAASH, a MODTRAN4 atmospheric correction package for hyperspectral data retrievals and simulations, Proceedings of the Seventh JPL Airborne Earth Science Workshop, 12-16 January, Jet Propulsion Laboratory, Pasadena, CA, pp. 9-14.

Akar, A., E. Gökalp, Ö. Akar, and V. Yılmaz, 2017. Improving classification accuracy of spectrally similar land covers in the rangeland and plateau areas with a combination of WorldView-2 and UAV images, Geocarto International, 32(9):990-1003.

Bandyopadhyay, M., J.A. van Aardt, and K. Cawse-Nicholson, 2013. Classification and extraction of trees and buildings from urban scenes using discrete return LiDAR and aerial color imagery, Proceedings SPIE 8731, Laser Radar Technology and Applications XVIII, 873105 .

Bauer, M.E., 1985. Spectral inputs to crop identification and condition assessment, Proceedings of the IEEE, 73(6):1071-1085.

Biard, F., and F. Baret, 1997. Crop residue estimation using multiband reflectance, Remote Sensing of Environment, 59(3):530-536.

Bunnik, N.J.J., 1978. The Multispectral Reflectance of Shortwave Radiation by Agricultural Crops in Relation with their Morphological and Optical Properties, Ph.D. dissertation, Agricultural University, Wageningen, The Netherlands, 176 p.

Bunting, P., and R. Lucas, 2006. The delineation of tree crowns in Australian mixed species forests using Compact Airborne Spectrographic Imager (CASI) data, Remote Sensing of Environment, 101(2):230-248.

Carter, G.A., 1994. Ratios of leaf reflectances in narrow wavebands as indicators of plant stress, International Journal of Remote Sensing, 15(3):697-703.

Chen, Q., D. Baldocchi, P. Gong, and M. Kelly, 2006. Isolating individual trees in a savanna woodland using small footprint lidar data, Photogrammetric Engineering \& Remote Sensing, 72(8):923-932.

Congalton, R.G., and K. Green, 2008. Assessing the Accuracy of Remotely Sensed Data: Principles and Practices, Second Edition, CRC press, Boca Raton, Florida, 183 p.

Congalton, R.G., R.G. Oderwald, and R.A. Mead, 1983. Assessing Landsat classification accuracy using discrete multivariate analysis statistical techniques, Photogrammetric Engineering \& Remote Sensing, 49(12):1671-1678.

Daughtry, C.S.T., 1990. Direct measurements of canopy structure, Remote Sensing Reviews, 5(1):45-60.

Daughtry, C.S.T., E.R. Hunt, and J.E. McMurtrey, 2004. Assessing crop residue cover using shortwave infrared reflectance, Remote Sensing of Environment, 90(1):126-134. 
DigitalGlobe, 2017. WorldView-2 Data Sheet, URL: http://www. spaceimagingme.com/downloads/sensors/datasheets/ WorldView2-DS-WV2-Web.pdf (last date accessed: 15 June 2018).

Dozier, J., 1989. Spectral signature of alpine snow cover from the Landsat Thematic Mapper, Remote Sensing of Environment, 28:9-22.

eoPortal Directory, 2017. WorldView-2, URL: https://directory. eoportal.org/web/eoportal/satellite-missions/v-w-x-y-z/ worldview-2 (last date accessed: 15 June 2018).

Foody, G.M., 2002. Status of land cover classification accuracy assessment, Remote Sensing of Environment, 80(1):185-201.

Fu, L., L. Zhang, and C. He, 2014. Analysis of agricultural land use change in the middle reach of the Heihe River Basin, Northwest China, International Journal of Environmental Research and Public Health, 11(3):2698-2712.

Gonzalez-Alonso, F., and J.M. Cuevas, 1993. Remote sensing and agricultural statistics: Crop area estimation through regression estimators and confusion matrices, International Journal of Remote Sensing, 14(6):1215-1219.

Graves, S.J., G.P. Asner, R.E. Martin, C.B. Anderson, M.S. Colgan, L. Kalantari, and S.A. Bohlman, 2016. Tree species abundance predictions in a tropical landscape with a supervised classification model and imbalanced data, Remote Sensing, 8(2):161.

Heenkenda, M.K., K.E. Joyce, S.W. Maier, and R. Bartolo, 2014. Mangrove species identification: Comparing WorldView-2 with aerial photographs, Remote Sensing, 6(7):6064-6088.

Horler, D.N.H., M. Dockray, and J. Barber, 1983. The red edge of plant leaf reflectance, International Journal of Remote Sensing, 4(2):273-288.

Huete, A.R., 1986. Separation of soil-plant spectral mixtures by factor analysis, Remote Sensing of Environment, 19(3):237-251.

Huete, A.R., and R.D. Jackson, 1987. Suitability of spectral indices for evaluating vegetation characteristics on arid rangelands, Remote Sensing of Environment, 23(2):213-232.

Ke, Y., and L.J. Quackenbush, 2011. A review of methods for automatic individual treecrown detection and delineation from passive remote sensing, International Journal of Remote Sensing, 32(17):4725-4747.

Kittler, J., and J. Illingworth, 1986. Minimum error thresholding, Pattern Recognition, 19(1):41-47.

Knipling, E.B., 1970. Physical and physiological basis for the reflectance of visible and near-infrared radiation from vegetation, Remote Sensing of Environment, 1(3):155-159. 
Kokaly, R.F., and R.N. Clark, 1999. Spectroscopic determination of leaf biochemistry using band-depth analysis of absorption features and stepwise multiple linear regression, Remote Sensing of Environment, 67(3):267-287.

Nagler, P.L., C.S.T. Daughtry, and S.N. Goward, 2000. Plant litter and soil reflectance, Remote Sensing of Environment, 71(2):207-215.

Peters, A.J., E.A. Walter-Shea, L. Ji, A. Vina, M. Hayes, and M.D. Svoboda, 2002. Drought monitoring with NDVI-based standardized vegetation index, Photogrammetric Engineering \& Remote Sensing, 68(1):71-75.

Pitkanen, J., 2001. Individual tree detection in digital aerial images by combining locally adaptive binarization and local maxima methods, Canadian Journal of Forest Research, 31(5):832-844.

Pouliot, D., and D. King, 2005. Approaches for optimal automated individual tree crown detection in regenerating coniferous forests, Canadian Journal of Remote Sensing, 31(3):255-267.

Pouliot, D.A., D.J. King, F.W. Bell, and D.G. Pitt, 2002. Automated tree crown detection and delineation in high-resolution digital camera imagery of coniferous forest regeneration, Remote Sensing of Environment, 82(2):322-334.

Pouliot, D.A., D.J. King, and D.G. Pitt, 2005. Development and evaluation of an automated tree detection-delineation algorithm for monitoring and regenerating coniferous forests, Canadian Journal of Forest Research, 35(10):2332-2345.

$\mathrm{Pu}, \mathrm{R}$., and S. Landry, 2012. A comparative analysis of high spatial resolution IKONOS and WorldView-2 imagery for mapping urban tree species, Remote Sensing of Environment, 124:516-533.

Quackenbush, L.J., P.F. Hopkins, and G.J. Kinn, 2000. Developing forestry products from high resolution digital aerial imagery, Photogrammetric Engineering \& Remote Sensing, 66(11):1337- 1348.

Ranson, K.J., C.S.T. Daughtry, L.L. Biehl, and M.E. Bauer, 1985. Sun-view angle effects on reflectance factors of corn canopies, Remote Sensing of Environment, 18(2):147-161.

Roberts, D.A., M.O. Smith, and J.B. Adams, 1993. Green vegetation, nonphotosynthetic vegetation, and soils in AVIRIS data, Remote Sensing of Environment, 44(2):255-269.

Roberts, D.A., B.W. Nelson, J.B. Adams, and F. Palmer, 1998. Spectral changes with leaf aging in Amazon caatinga, Trees, 12(6):315- 325.

Rouse Jr., J.W., R.H. Haas, J.A. Schell, and D.W. Deering, 1974. Monitoring vegetation systems in the Great Plains with ERTS, NASA Special Publication, 351:309-317.

Serbin, G., C.S.T. Daughtry, E.R. Hunt, J.B. Reeves, and D.J. Brown, 2009. Effects of soil composition and mineralogy on remote sensing of crop residue cover, Remote Sensing of Environment, 113(1):224-238. 
Soil Survey Staff, 2018. Natural Resources Conservation Service, United States Department of Agriculture. Official Soil Series Descriptions, URL: https://soilseries.sc.egov.usda.gov/ (last date accessed: 15 June 2018).

Stoner, E.R., and M.F. Baumgardner, 1981. Characteristic variations in reflectance of surface soils, Soil Science Society of America Journal, 45(6):1161-1165.

van Leeuwen, W.J.D., 2009. Visible, near-IR, and shortwave IR spectral characteristics of the terrestrial surfaces, The SAGE Handbook of Remote Sensing (T.A. Warner, M.D. Nellis, and G.M. Foody, editors), UK, SAGE Publications, pp. 33-50.

Wang, L., P. Gong, and G.S. Biging, 2004. Individual tree-crown delineation and treetop detection in high-spatial-resolution aerial imagery, Photogrammetric Engineering \& Remote Sensing, 70(3):351-357.

Weatherbase, 2017. Beltsville, MD Koppen Climate Classification, URL: http://www.weatherbase.com/weather/weather- summary. php3?s $=7081 \&$ cityname $=$ Beltsville $\% 2 C+$ Maryland $\% 2 C+$ United + States + of + America\&units $=$ (last date accessed: 15 June 2018).

White, D.C., M.M. Lewis, G. Green, and T.B. Gotch, 2016. A generalizable NDVI-based wetland delineation indicator for remote monitoring of groundwater flows in the Australian Great Artesian Basin, Ecological Indicators, 60:1309-1320.

Wu, M.F., Z.C. Sun, B. Yang, and S.S. Yu, 2017. Synergistic use of WorldView-2 imagery and airborne LiDAR data for urban land cover classification, IOP Conference Series: Earth and Environmental Science (Vol. 57, No. 1, p. 012035), IOP Publishing.

Ye, W., X. Li, X. Chen, and G. Zhang, 2014. A spectral index for highlighting forest cover from remotely sensed imagery, SPIE Asia Pacific Remote Sensing: 92601L92601L.

Yuan, F., K.E. Sawaya, B.C Loeffelholz, and M.E. Bauer, 2005. Land cover classification and change analysis of the Twin Cities (Minnesota) Metropolitan Area by multitemporal Landsat remote sensing, Remote Sensing of Environment, 98(2):317-328.

Zhang, K., and B. Hu, 2012. Individual urban tree species classification using very high spatial resolution airborne multi- spectral imagery using longitudinal profiles, Remote Sensing, 4(6):1741-1757.

Zhang, L., X. Sun, T. Wu, and H. Zhang, 2015. An analysis of shadow effects on spectral vegetation indexes using a ground-based imaging spectrometer, IEEE Geoscience and Remote Sensing Letters, 12(11):2188-2192. 


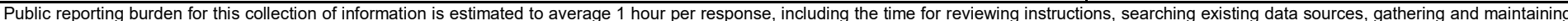

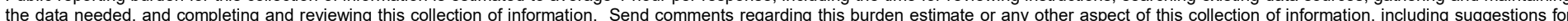

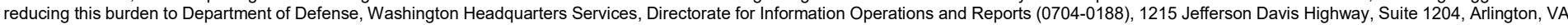

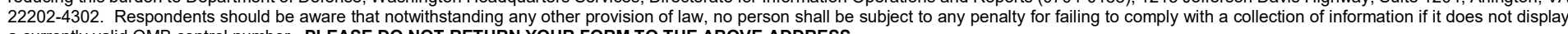
a currently valid OMB control number. PLEASE DO NOT RETURN YOUR FORM TO THE ABOVE ADDRESS.
1. REPORT DATE (DD-MM-YYYY)
March 2019

4. TITLE AND SUBTITLE

Robust Forest Cover Indices for Multispectral Images
3. DATES COVERED (From - To)

5a. CONTRACT NUMBER

5b. GRANT NUMBER

5c. PROGRAM ELEMENT NUMBER

5d. PROJECT NUMBER

405906, 405908, 0602784A-855-24, and

62784.

5e. TASK NUMBER

5f. WORK UNIT NUMBER

8. PERFORMING ORGANIZATION REPORT NUMBER

ERDC/GRL MP-19-1

Geospatial Research Laboratory

7701 Telegraph Rd.

Alexandria, VA 22315-3864

9. SPONSORING / MONITORING AGENCY NAME(S) AND ADDRESS(ES)

Headquarters, U.S. Army Corps of Engineers

Washington, DC 20314-1000
10. SPONSOR/MONITOR'S ACRONYM(S)

11. SPONSOR/MONITOR'S REPORT NUMBER(S)

\section{DISTRIBUTION / AVAILABILITY STATEMENT}

Approved for public release; distribution unlimited.

\section{SUPPLEMENTARY NOTES}

\section{ABSTRACT}

Trees occur in many land cover classes and provide significant ecosystem services. Remotely sensed multispectral images are often used to create thematic maps of land cover, but accurately identifying trees in mixed land-use scenes is challenging. We developed two forest cover indices and proto- cols that reliably identified trees in WorldView-2 multispectral images. The study site in Maryland included coniferous and deciduous trees associated with agricultural fields and pastures, residential and commercial buildings, roads, parking lots, wetlands, and forests. The forest cover indices exploited the product of either the reflectance in red (630 to $690 \mathrm{~nm})$ and red edge (705 to $745 \mathrm{~nm}$ ) bands or the product of reflectance in red and near infrared (770 to $895 \mathrm{~nm}$ ) bands. For two classes (trees versus other), overall classification accuracy was $>77$ percent for the four images that were acquired in each season of the year. Additional research is required to evaluate these indices for other scenes and sensors.

$\begin{array}{lll}\text { 15. SUBJECT TERMS } & \text { Trees } & \text { Land cover--Remote sensing } \\ & \text { Forest canopies } & \text { Multispectral imaging }\end{array}$

\section{SECURITY CLASSIFICATION OF:}

\begin{tabular}{l|l} 
a. REPORT & b. ABSTRACT \\
UNCLASSIFIED & UNCLASSIFIED
\end{tabular}

c. THIS PAGE

UNCLASSIFIED
17. LIMITATION OF ABSTRACT

\section{NUMBER OF PAGES}

35 19a. NAME OF RESPONSIBLE PERSON

19b. TELEPHONE NUMBER (include area code) 